\title{
A CRITICAL REVIEW OF THE STATE-OF-THE-ART OF FRACTURE MECHANICS WITH EMPHASIS ON LAYERED ROCKS
}

By

M. D. Kuruppu

K. P. Cheng

J. N. Edl, Jr.

July 1983

For

U.S. Department of Energy

Office of Fossil Energy

Morgantown Energy Technology Center

Laramie Project Office

Laramie, Wyoming

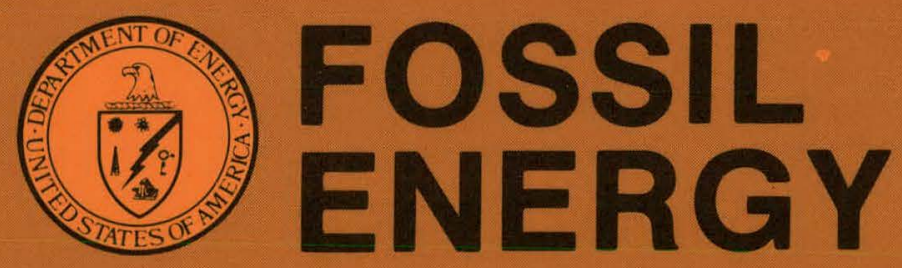

Technical Information Center

Office of Scientific and Technical Information

United States Department of Energy 


\section{DISCLAIMER}

This report was prepared as an account of work sponsored by an agency of the United States Government. Neither the United States Government nor any agency Thereof, nor any of their employees, makes any warranty, express or implied, or assumes any legal liability or responsibility for the accuracy, completeness, or usefulness of any information, apparatus, product, or process disclosed, or represents that its use would not infringe privately owned rights. Reference herein to any specific commercial product, process, or service by trade name, trademark, manufacturer, or otherwise does not necessarily constitute or imply its endorsement, recommendation, or favoring by the United States Government or any agency thereof. The views and opinions of authors expressed herein do not necessarily state or reflect those of the United States Government or any agency thereof. 


\section{DISCLAIMER}

Portions of this document may be illegible in electronic image products. Images are produced from the best available original document. 


\title{
DISCLAIMER
}

\begin{abstract}
This report was prepared as an account of work sponsorcd by an agency of the United States Government. Neither the United States Government nor any agency thereof, nor any of their employees, makes any warranty, express or implied, or assumes any legal liability or responsibility for the accuracy, completeness, or usefulness of any information, apparatus, product, or process disclosed, or represents that its use would not infringe privately owned rights. Reference herein to any specific commercial product, process, or service by trade name, trademark, manufacturer, or otherwise does not necessarily constitute or imply its endorsement, recommendation, or favoring by the United States Government or any agency thereof. The views and opinions of authors expressed herein do not necessarily state or reflect those of the United States Government or any agency thereof.
\end{abstract}

This report has been reproduced directly from the best available copy.

Available from the National Technical Information Service, U. S. Department of Commerce, Springfield, Virginia 22161.

Price. Printal Cupy A03

Microfiche A01

Codes are used for pricing all publications. The code is determined by the number of pages in the publication. Information pertaining to the pricing colles can be found in the current issues of the following publications, which are generally available in most libraries: Energy Research Abstracts (ERA); Guvernment Reports Announcements and Index (GRA and 1); Scientific and Technical Abstract Reports (STAR); and publication NTIS-PR-360 available from NTIS at the above address. 
DOE/METC/84-12

(DE84003068)

Distribution Category UC-91

\title{
A CRITICAL REVIEW OF THE STATE-OF-THE-ART OF FRACTURE MECHANICS WITH EMPHASIS ON LAYERED ROCKS
}

\author{
By \\ M. D. Kuruppu \\ K. P. Cheng \\ J. N. Edl, Jr. \\ July 1983 \\ For \\ U.S. Department of Energy \\ Office of Fossil Energy \\ Morgantown Energy Technology Center \\ Laramie Project Office \\ Laramie, Wyoming 82071
}


THIS PAGE

\section{WAS INTENTIONALLY LEFT BLANK}


CONTENTS

$\underline{\text { Page }}$

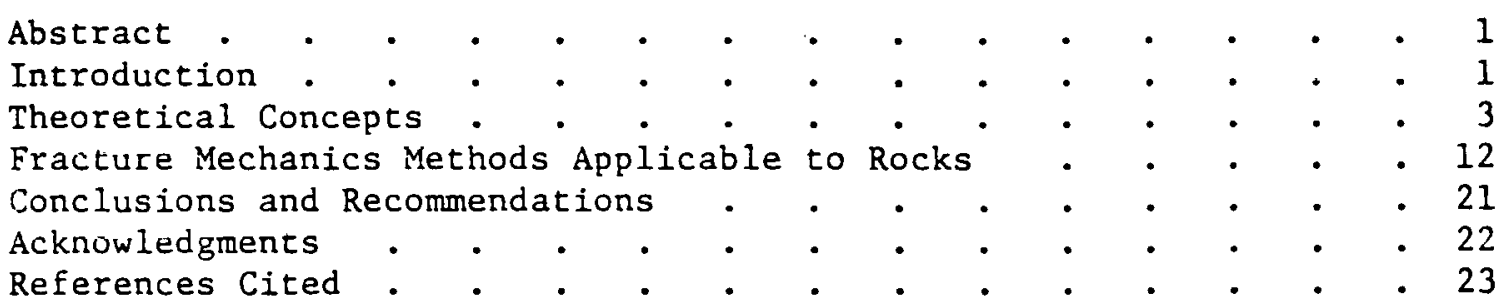

\section{ILLUSTRATIONS}

1. Basic modes of loading involving different crack surface

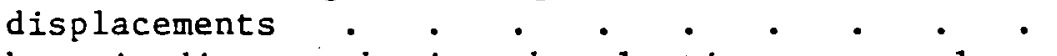

2. The schematic diagram showing the elastic energy release interpretation of $G$ as the difference of area between curves corresponding to two specimens which differ only in respect to their crack lengths . . . . . . 4

3. Path of J-integral evaluation surrounding a crack : . . $\quad 5$

4. Representation of a Griffith crack and the energy associated wiLlı $1 L$.

5. Compliance method of fracture toughness determination . . . 9

6. Sharp crack under biaxial loading . . . . . . . . 14

7. Specimen configurations showing crack orientations with respect to the bedding planes . . . . . . . 16

8. Split cylinder test configuration . . . . . . . . . 18

9. Reinforced double cantilever beam with possible loading

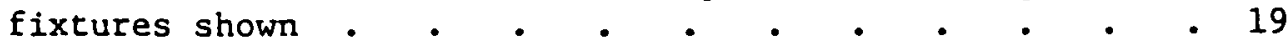

10. Quarter point isoparametric crack tip element . . . . . 20 


\title{
A CRITICAL REVIEW OF THE STATE-OF-THE-ART OF FRACTURE MECHANICS WITH EMPHASIS ON LAYERED ROCKS ${ }^{a}$
}

\section{By}

Mahinda D. Kuruppul, Ken P. Chong ${ }^{2}$, and John N. Edl, Jr. 3

\begin{abstract}
(1)
ABSTRACT

This paper presents results of a literature survey of over 70 pertinent publications and critical reviews of fracture mechanics emphasizing the fracture behavior of layered rocks. Historical perspective, fracture mechanisms, linear and nonlinear fracture mechanics, energy theories, ductile and brittle fractures, process regions, specific work of fracture, J-integrals, failure theories, static and dynamic fractures, rock fracture mechanics, fracture toughness of layered rocks (e.g., oil shale), experimental and numerical methods are reviewed and discussed. Innovative and promising methods tailored for the fracture mechanics of layered rocks are recommended.
\end{abstract}

\section{INTRODUCTION}

Fracture mechanics deals with the separation of materials under stress. The critical stress of fracture, however, is found to be much lower than that needed for interatomic bond separation. This is due to the existence of material inhomogeneities such as micro-cracks, grain boundaries, foreign particles, crystal defects, etc., which cause local stress concentrations leading to the lowering of resistance to failure. Macroscopic scale inhomogeneities, such as bedding planes in rocks, may also weaken the material. Griffith [1] put forward a satisfactory theory which formed the foundation for the development of the theory of linear elastic fracture mechanics (LEFM). Essentially, Griffith based his theory on energy balance associated with the process of fracture and equated the release of elastic potential energy during crack growth under constant load-point displacement to the increase of surface energy of the newly created surface. "Surface energy" could be different from the energy required for interatomic bond separation as the fracture is considered to occur due to the coalescence of micro-cracks and other material defects under load. However, this theory was found not directly applicable to

\footnotetext{
${ }^{a}$ Sponsored by U.S. Department of Energy under Contract No. AS20-82LC10961, Dr. Theodore C. Bartke, COR.

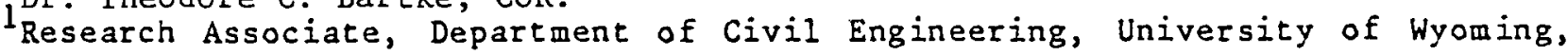
Laramie, WY.

2 Professor, Department of Civil Engineering, University of Wyoming, Laramie,

$3_{\text {Research Mining Engineer, Division of Engineering, Laramie Energy Techno- }}^{\text {WY }}$ logy Center, DOE, Laramie, WY. (Died July 31, 1983)
} 
the fracture of ductile materials in which irreversible plastic deformations occur near the crack tip.

Griffith's theory was subsequently modified by Orowan [2] who proposed that the release of elastic strain energy is equal to the plastic energy dissipation and the energy required for the formation of the new surface. Fracture of most types of rock is also associated with a high degree of nonlinear deformations at the crack tip due to the microcracking. Further, Irwin [3] postulated that the elastic energy release rate, as applied to elastic bodies, can be related to the stress intensity factor which is a measure of the strength of the elastic singularity of the crack tip strain field. Barenblatt [4] introduced the concept of autonomy where it is required to achieve a unique state at the neighborhood of the crack tip for the initiation of fracture, and this concept was later extended by Broberg [5] who suggested the existence of an autonomous "process region" in the immediate vicinity of the crack tip and claimed that it is applicable to the fracture of nonlinear materials as well. The process zone is embedded in a much larger nonlinear zone which; again, is surrounded by an elastic crack t1p zone. In metallic materials, the nonlinear deformations are due to yielding; and in rock materials, they are due mainly to a high degree of microcracking [60].

It would be very desirable if the fracture process could be understood well in terms of micro-separation mechanisms themselves. The main reason for the fracture of a structure is the presence of material inhomogeneities. The simplest case of fracture would be that caused by the separation of atomic planes or grain boundaries, known as cleavage fracture. Micro-separations always start at certain specific sites such as inclusions. Macroscale inhomogeneities such as orthotropy, porosity, foreign particles, bedding planes, etc., also help initiate fracture. All of the above mentioned factors account for the complexity of formulating a general fracture theory based on the micromechanisms only. In the continuum mechanics approach, the fracture process is treated only in terms of loading, geometry, material properties, environmental conditions, etc.

The theory of LEFM by its nature is applicable only to those cases where the crack tip nonlinear zone is confined to a very small region around the crack tip and the stress field associated with the crack tip is mainly elastic. However, in the case of elastic-plastic material and most types of rock, the extent of the crack tip's nonlinear zone could be substantial, compared to the overall crack geometry. With the development of nonlinear fracture mechanics, it has been possible to characterize nonlinear crack tip fields, at least until the onset of crack growth, using parameters such as: J-integral [6], strain energy density factor, $S[1]$, and crack opening displacement ( $C \cup D)$ [8], In the same way that the critical stress intensity factor ( $K_{I C}$ ) and COD characterize linear elastic crack tip fields under confined yielding. With the recent advances in stress analysis methods, such as the development of non-linear finite element methods and with improved test methods such as the use of computer-aided material test methods, rapid progress has been made recently in the study of fracture of materials having non-linear properties. 


\section{THEORETICAL CONCEPTS}

2.1 Definitions and relationships between basic parameters of linear elastic fracture mechanics theory

A smooth notch in a uniformly stressed elastic body gives rise to a stress concentration. The magnitude of such stress concentration $c$ an be measured using a stress concentration factor which may be defined as the ratio of the maximum stress at the tip of the notch to the uniformly applied stress. In the case of a sharp crack, the theoretical elastic stress at the crack tip becomes infinite and, therefore, the stress concentration factor cannot be used to distinguish between different cracks. The concept of the stress intensity factor (SIF) has been proposed to overcome this difficulty. The stress associated with a crack tip is represented by

$$
\sigma_{i j} \cong \frac{K N}{\sqrt{2 \pi r}}
$$

where $\sigma_{i j}$ is the stress at a small distance $r$ from the crack tip, and the constant of proportionality, $\mathrm{K}_{\mathrm{N}}$, is defined as the stress intensity factor. Three kinds of factors are defined, depending on the relative displacements of crack surfaces, and are denoted by $K_{I}, K_{I I}$, and $K_{I I I}$. These displacement components are illustrated in Fig. 1 , denoted as an opening mode (Mode I), an in-plane shear mode (Mode II), and an antiplane shear mode (Mode III). In opening mode, the crack surfaces move directly apart, and in in-plane shear mode, the crack surfaces slide over one another in a direction perpendicular to the leading edge of the crack. In antiplane shear mode, the crack surfaces move relative to one another and parallel to the leading edge of the crack. Mode I loading is encountered in a majority of engineering situations involving cracked components, whereas Modes II and III are less frequent in occurrence. An example for mixed Mode I and Mode II is a rectangular plate under uniaxial stress and having a center crack inclined to the direction of stress. A notched round bar under torsion is a pure Mode III case.

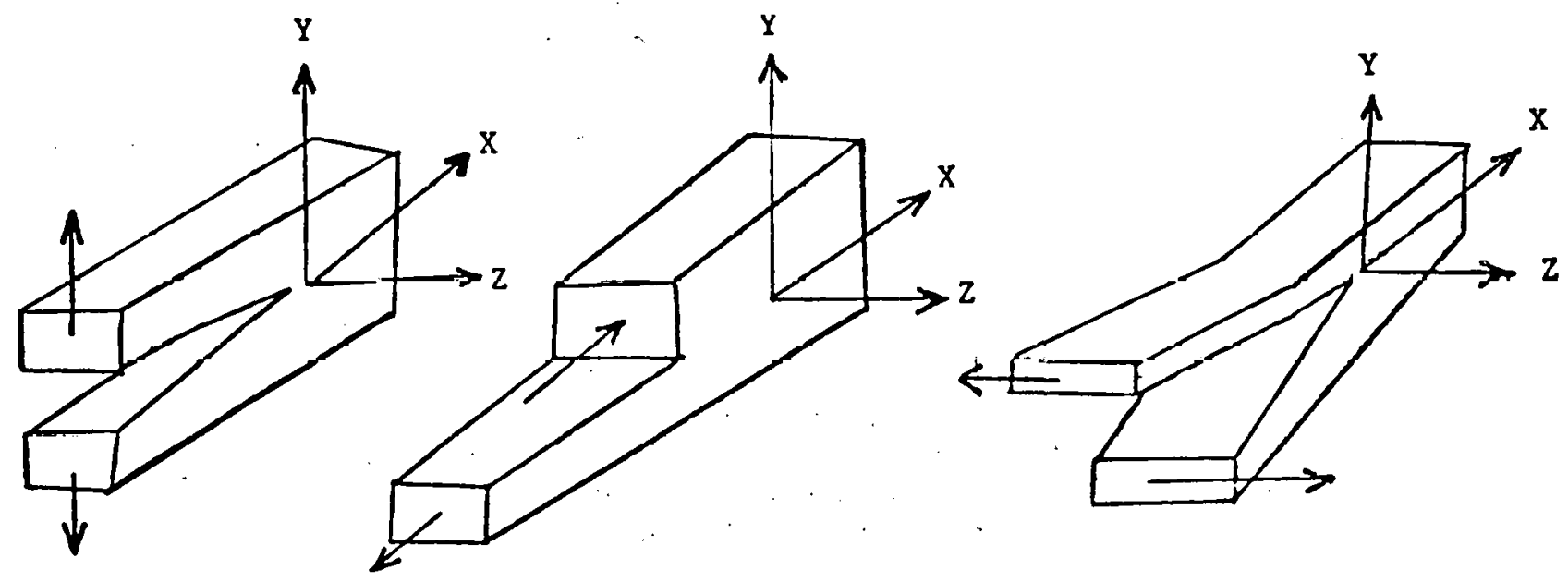

Figure 1. Basic modes of loading involving different crack surface displacements 
The elastic stress singularity, as given in expression (1), is considered to be of $1 / \sqrt{x}$ type. For the case of a large plate containing a crack of length $2 a$ and subjected to a uniform stress $\sigma_{0}$ remote from and perpendicular to the crack, the stress intensity factor is given by

$$
K_{I}=\sigma_{0} \sqrt{\pi a}
$$

The usefulness of the stress intensity factor lies in its ability to interpret the stress field associated with the crack tip. In order to determine the stress field, it is necessary to have a knowledge of the SIF only. Conversely, if the crack tip stress field is known, the SIF may also be determined. When the external load applied to a cracked body is increased so that the crack will start to grow, the stress intensity factor corresponding to the onset of crack growth is defined as the critical stress intensity factor $\mathrm{K}_{\mathrm{NC}}$ of the particular mode $\mathrm{N}$.

Griffith's theory postulates that the energy expended for the crack surface formation is supplied by the potential energy released by the material. Consequently, the elastic energy release rate may be expressed as [1]

$$
G=-\frac{1}{B} \frac{\partial P}{\partial a}
$$

where $P$ is the potential energy, $a$ is the crack length, and $B$ is the thickness of the cracked specimen.
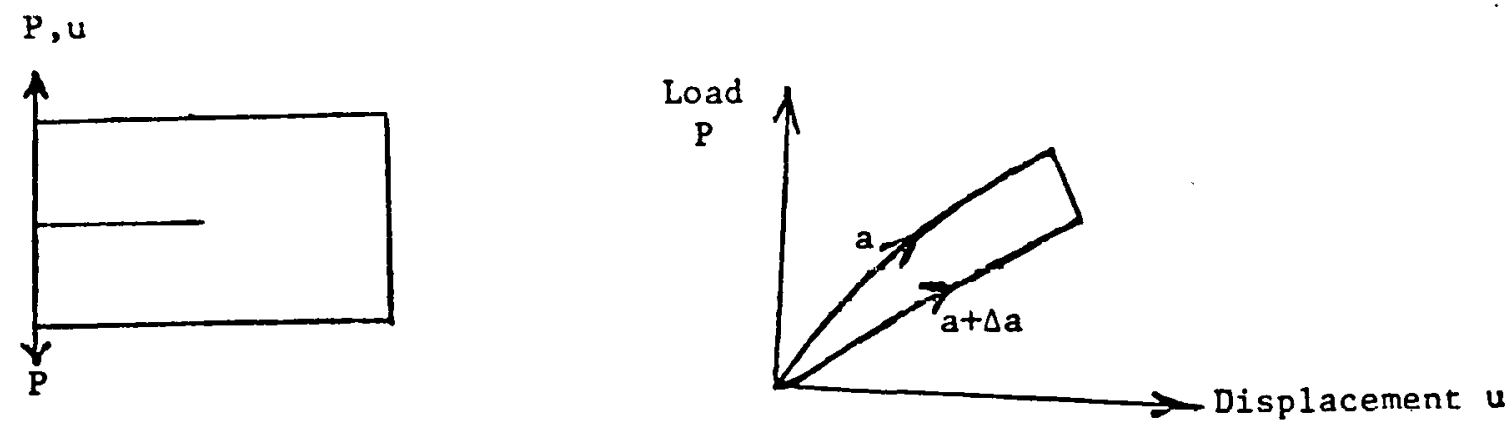

Figure 2. The schematic diagram showing the elastic energy release interpretation of $G$ as the difference of area between curves corresponding to two specimens which differ only in respect

to their crack lengths 
For linear elastic fracture cases, $G$ is related to SIF as [17]

$$
G=\frac{1-v^{2}}{E}\left(K_{I}^{2}+K_{I I}^{2}\right)+\frac{1+v}{E} K_{I I I}^{2}
$$

where $K_{I}, K_{I I}$, and $K_{I I I}$ are stress intensity factors of different displacement modes in plane strain. In particular, for Mode I case, one may write [17]

$$
\mathrm{K}_{\mathrm{I}}^{2}=\mathrm{G} \mathrm{E}^{1}
$$

where $E^{l}=E /\left(1-v^{2}\right)$ for $p l a n e$ strain and $E^{l}=E$ for plane stress. An indirect method for the determination of SIF based on energy is by evaluating the Jintegral around a contour surrounding the "crack tip as [6]

$$
J=\int_{\Gamma}\left(W d y-\sigma_{i j} n_{j} u_{i, x} d s\right)
$$

where $W$ is the strain energy density, $\Gamma$ is any curve which surrounds the crack tip in a counterclockwise sense starting from any point on the lower crack surface and ending at any point on the upper crack surface. $n_{j}$ is the outward unit vector normal to the curve and $S$ is the arc length. It $c$ an be shown that $\mathrm{J}$-integral is path independent and represents the energy release

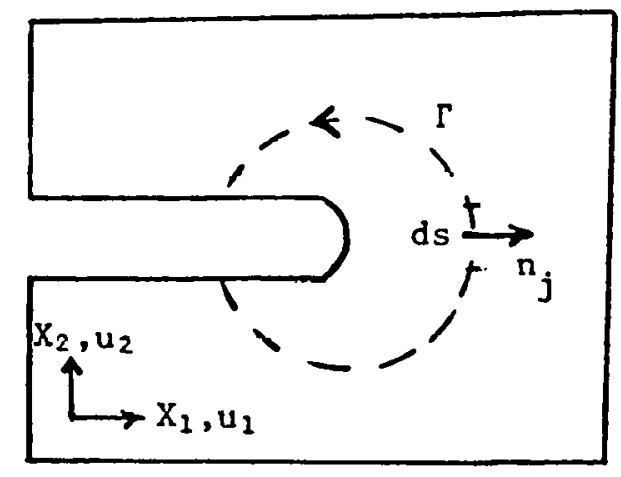

Figure 3. Path of J-integral evaluation surrounding a crack

rate if the strain energy density can be expressed as a function of the current strain tensor, $\varepsilon_{i} j$, and temperature, $T$, so that the stress tensor $\sigma_{i j}$ can be expressed in the form $\frac{\partial W}{\partial \varepsilon_{i j}}$ where $W=f\left(\varepsilon_{i j}, T\right)$. For cases where LEFM.

is applicable, one has

$$
J=G
$$


J-integral provides a satisfactory method for analytical study of crack tip field employing a deformation theory of plasticity. Path independence of $\mathrm{J}$ is strictly valid as long as the deformation plasticity theory is applicable for deformation of the material. J-integral has been used for characterizing the crack tip field under conditions where the extent of nonlinear defcrmation exceeds that satisfying LEFM. Hutchinson [61] and Rice and Rosengren [62] have presented the near tip field associated with a crack tip of a nonlinear material using J-integral as the strength of the singularity. J-integral is capable of characterizing crack tip fields up to fully plastic condition.

\subsection{Theories of failure}

The earliest successful fracture criterion was put forward by Griffith [1] who considered the energy balance between the elastic strain energy available for crack propagation and the surface energy of the newly created crack, assuming that the crack propagates under cunstaut load point displacement. This theory has been particularly successful with brittle solids in which the fracture is associated wich negligible unulitied or duetile deformations. Consider a body containing an elliptical crack of length 2 c under a stress $\sigma$ applied normal to and away from the crack. Assuming that the external stress is held constant while the crack grows, one has

$$
\frac{\partial}{\partial c}(W-4 \alpha c B)=0
$$
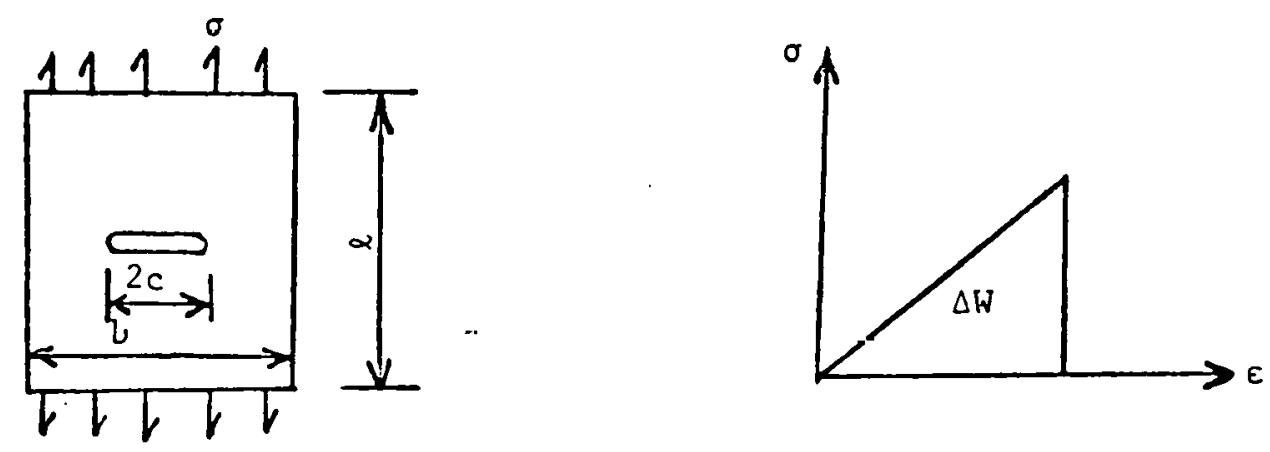

Figure 4. Representation of a Griffith crack and the energy associated with it

where $W$ is the elastic strain energy of the body, $\alpha$ is the surface energy per unit crack surface area, and $B$ is the specimen thickness. The strain energy of the cracked body may be considered to be consisting of that of the same body without the crack, $W_{0}$, and that due to the crack, $W_{c}$; that is,

$$
W=W_{0}+W_{c}
$$


Using Equations ( 8 ) and (9) and substituting for the respective strain energy quantities [9], there results

$$
\begin{gathered}
\frac{\partial}{\partial c}\left[\frac{1}{2} \frac{\sigma^{2}}{E} b \ell B+\frac{\pi \sigma^{2} c^{2} B}{E}-4 \alpha c B\right]=0 \\
\text { or } \quad \pi \sigma^{2} c=.2 \alpha E
\end{gathered}
$$

The critical tensile stress $\sigma_{c}$ at which the crack begins to grow is given as

$$
\sigma_{c}=\left(\frac{2 \alpha E}{\pi c}\right)^{\frac{1}{2}}
$$

for plane stress, and

$$
\sigma_{c}=\left[\frac{2 \alpha E}{\pi\left(1-v^{2}\right) c}\right]^{\frac{1}{2}}
$$

for plane strain. Most brittle materials, such as rocks, fail due to the achievement of a critical tensile principal stress within the material, and the ability of Griffith criterion to explain such failure as given by Equations (11a) and ( $11 b$ ) has enhanced its usefulness for similar applications.

The critical value of the elastic strain energy release rate, $G_{I C}$, has been postulated to be a satisfactory fracture criterion in LEFM [10]. At the point of fracture initiation $\mathrm{K}_{I C}$ is capable of describing the state of stresses and strains in the fracture process zone. GIf retains its validity as a characterizing parameter, even in the presence of considerable nonlinear deformations, as long as the fracture process is within the limits of small scale yielding [11]. The critical value of the elastic strain energy release rate has been identified as a material property provided the fracture specimens satisfy certain dimensional requirements, and this value is referred to as the fracture toughness. Following a series of successful experiments, Begley and Landes [12] were able to demonstrate that the J-integral value at the onset of crack growth in plane strain, $J_{I C}$, is a fracture characterizing parameter for nonlinear elastic material as well. The state of stress and strain at crack initiation $c a n$ be characterized by $J_{I C}$, even if the nonlinear zone is substantial compared to the specimen dimensions. However, the size of the process zone must be smaller than the characteristic plastic field zone. As in the case of the validity of $K_{I C}$, there is a minimum size requirement [12] that must be satisfied to obtain a valid plane strain JIC value which can be associated with a material property. For a specimen which does not satisfy the necessary dimensional requirements, the triaxial constraint may diminish, and the critical value of J-integral may become thickness dependent. In the linear elastic range, both $K$ and $J$ are equally applicable as fracture characterizing parameters. At the point of fracture initiation, both $K_{I C}$ and $J_{I C}$ are capable 
of describing the state of stresses and strains in the process zone. For linear elastic materials,

$$
J_{I C}=G_{I C}
$$

It should be emphasized that the definition of J-integral assumes the deformation laws of plasticity and that all tests done for the determination of fracture toughness use monotonic loading only.

The strain energy density theory was proposed by Sih [13], originally for linear elastic fracture, and was later extended to explain non-linear fracture and slow stable crack growth as well [7]. The crack initiation and slow crack growth is assumed to be governed by

$$
\left(\frac{\Delta W}{\Delta V}\right)_{c}=\frac{s_{c}}{r_{L}}=\text { Constant }
$$

where $(\Delta W / \Delta V)_{c}$ refers to the critical strain energy density, $S_{c}$ is the critical strain energy density factor, and $r_{c}$ is a certain critical length parameter. The location and the direction of the fracture initiation is described by

$$
\mathrm{s}_{\mathrm{c}}=\mathrm{s}_{\mathrm{min}}
$$

and this minimum value is postulated to be a constant for a given material. The two basic ways that a material element can store energy are by dilatation and/or distortion. The former is associated with change in volume, and the latter is associated with change in shape. Fracture surface usually consists of flat and slant portions (i.e., plane strain and plane stress portions of fracture), even though the latter is not prominent in brittle fractures. Sih's theory [13] further proposes that the ratio of the extent of flat to slant fracture is proportional to the ratio ot $(\Delta W / \Delta V) \mathrm{V}$ and $(\Delta W / \Delta V) \mathrm{d}$ which are the components of strain energy density associated with dilatation and distortion, respectively. Therefore,

$$
\frac{A_{E}}{A_{S}}=\frac{(\Delta W / \Delta V)_{V}}{(\Delta W / \Delta V)_{d}}
$$

where $A_{f} / A_{S}$ is the ratio of flat to slant fracture area. The fracture toughness is concerned only with the elastic fracture and, hence, is considered to be a constant, even in the presence of large nonlinear deformations associated with fracture.

The Dugdale "strip-yield" model provides a simple model for representing a crack with yielding ahead of its tip. Wells [8] identified the significance of the crack opening displacement as a fracture-characterizing parameter and proposed the attainment of its critical value as a fracture criterion. Crack 
opening displacement, $\delta_{c}$, has been successful in taking into account the considerable amount of crack tip non-linearity associated with fracture in high toughness materials. By incorporating COD fracture criterion in the Dugdale yield model, fracture toughness, $G_{C}$, is related to COD by wells [8,14] as

$$
\mathrm{G}_{\mathrm{c}}=\mathrm{mo}_{\mathrm{y}} \delta_{\mathrm{c}}
$$

where $\sigma_{y}$ is the yield strength of the material in simple tension and $m$ is a constant which depends on the condition at the crack tip.

\subsection{Fracture toughness}

To describe the fracture initiation process of a material, a certain length parameter should be chosen to be associated with the characteristic stress and strain field. This could be the radius of the fracture process zone around the crack tip. The concept of autonomy [4] assumes that within the process zone, the same mechanical events always occur in specimens made of the same material and of the same thickness during loading until crack growth occurs. The situation of the process zone is. expected to be controlled by the continuum stress and strain field surrounding it. Hence, the stress and strain field within this region is also governed by the value of $K$, the stress intensity factor. At the point of fracture initiation, the stress and strain field in the fracture process zone assumes a unique state and is fully described by the critical stress intensity factor, KIC, or the fracture

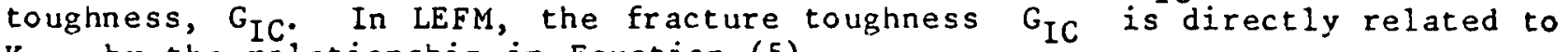
$\mathrm{K}_{\mathrm{IC}}$ by the relationship in Equation (5).

\subsubsection{Determination of fracture toughness using compliance methods}
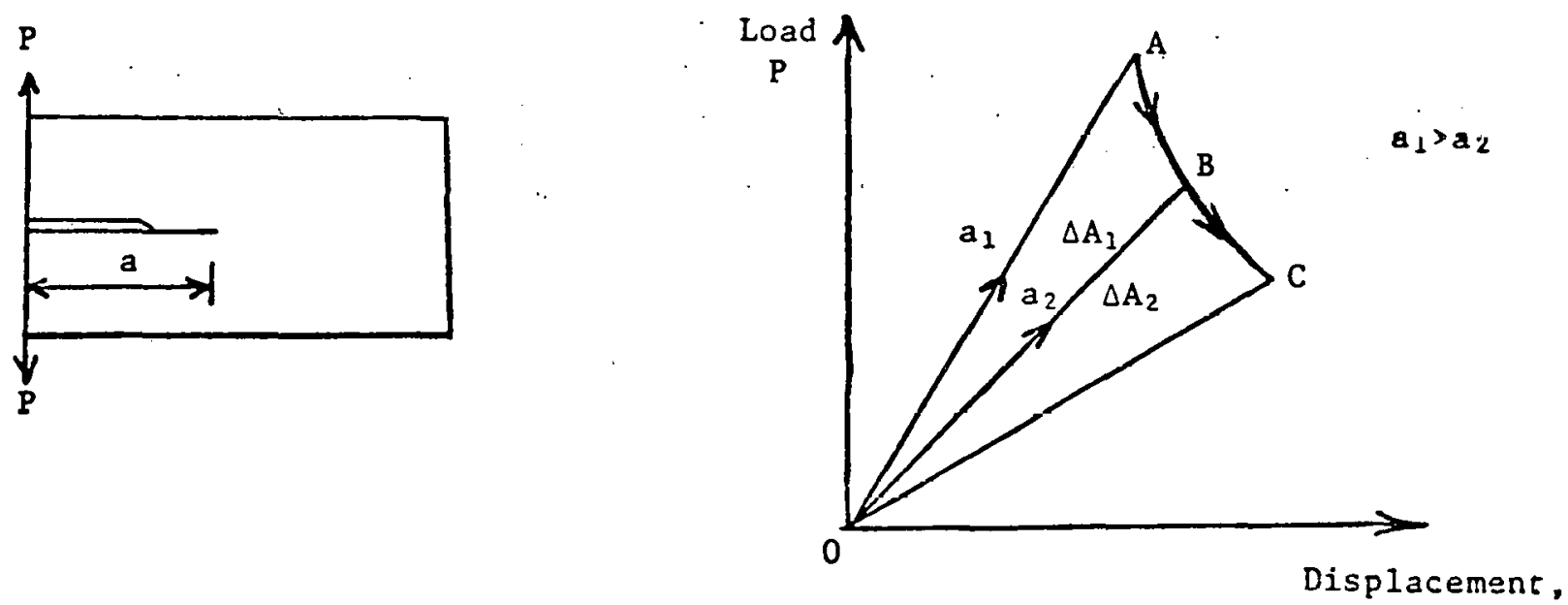

$\mathbf{u}$

Figure 5. Compliance method of fracture toughness determination 
Following the method proposed by Gurney, et al. [15], the fracture toughness of a material can be evaluated graphically by measuring the area representing the change of the stored elastic energy in the syster which is then divided by the incremental crack growth as shown by the relationship (3). The specimen is usually fatigue precracked at a maximum load level not exceeding the estimated $K_{I C}$ value of the material and tested in monotonic loading past the critical load that the specimen can sustain. The applied load, $P$, the load point displacement, $u$, and the crack extension, $\Delta a$, are measured using appropriate transducers and gages. A typical load-displacement plot for two initial crack lengths is shown in Figure 5. In general, for elastic materials, P-u behavior follows a straight line. Following the initial loading, at point $A$, a critical load is reached and the crack begins to extend. The strain energy required to produce a unit change in crack surface area is the fracture toughness of the material, and this energy is supplied by the strain energy stored in the body and by external work during the crack growth. It is assumed that the strain rate is slow enough for the crack to propagate under quasi-static conditions. The area $O A B$ is directly associated with fracture toughness as

$$
K_{I C}=G_{I C}=\frac{1}{B} \frac{\Delta A}{\Delta a}
$$

where $\triangle A$ denotes the area $O A B, \Delta a$ is the crack extension, and $B$ is the specimen thickness.

It is an inherent advantage of this method that a number of measures of $G$ can be determined from a single test. It is found that regardless of the sector area used, $G$, being a material property, remains constant, and curve $A B C$ depicts a constant $G$ locus.

Specimens used for plane strain fracture toughness testing are required to exceed certain minimum. size criteria for the results to be valid [16]. These size requirements are intended to contain the plastic zone size at fracture to a very small fraction of typical specimen dimensions in order to produce smallscale yielding conditions and reduce through thickness deformations and loss of plane strain constraint. They are

$$
B, a,(W-a) \geq 2.5\left(K_{I C} / \sigma_{y}\right)^{2}
$$

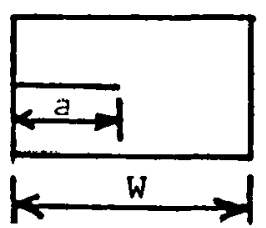

where $B$ is the specimen thickness, $a$ is the crack length and $W$ is the width. The plane strain fracture toughness is denoted as $\mathrm{K}_{I C}$. 


\subsubsection{Fracture Resistance}

It is well known that the fracture process of a cracked body is usually not comprised of a sudden failure from initial crack growth to total failure. Substantial stable crack growth precedes fast fracture in metallic material of high fracture tougrness, as well as in most types of rock [46,63]. The extent of stable growth can be considerable, unlike the case of brittle material. The initial phase of crack growth is quasi-static in which dynamic effects are negligible and the release of strain energy is associated with the material separation, shear lip formation, as well as with the growth of the nonlinear zone around the crack tip. Consequently, the fracture resistance increases with crack growth, thus causing the fracture tougnness value corresponding to initiation, a less significant parameter. It is widely accepted that $G_{I C}$ (or $\mathrm{K}_{\mathrm{IC}}$ ) measures the intensity of the crack tip field associated with the crack initiation in a plane strain case; and, in a similar manner, the crack growth resistance curve ( $R$-curve) measures the strength of the crack tip field of a growing crack before the commencement of unstable growth. The crack growth resistance curve $c$ an be either J-based or COD-based and $c$ an be a material property depending on the condition of the crack tip and for limited crack growth in which J or COD uniquely characterizes the fracture process zone $[64,65]$. In most cases of fracture associated with high toughness materials, R-curves exhibit a steady upper value denoted as $J_{R_{0}}$, and this value may be more appropriately considered as the critical fracture toughness $[66,67]$. However, the determination of $R$-curve for rock material is difficult as the crack extension determination in rock does pose a problem.

The specific work of fracture $\bar{R}$ has been used to describe the fracture energy associated with rock material $[68,71]$. It 1 s defined as

$$
\overline{\mathrm{R}}=\frac{1}{\mathrm{~A}}(W-E)
$$

where $W$ is the work done by the applied forces, $E$ is the strain energy of the specimen, and $A$ is the net section area of the specimen. During slow stable crack growth of rock materials, $\bar{R}$ is found to increase up to a point and then reaches a steady level as the crack continues to grow [22]. For the plane strain case, this plateau level may be considered as a material property for rock.

\subsection{Dynamic fracture and crack arrest}

Dynamic effects are generally ignored in cases where the crack propagations take place quasi-statically. The fracture toughness of a inaterial, $\mathrm{K}_{I C}$ (or $\mathrm{G}_{I C}$ ), and the resistance of the material for quasi-static crack growth, $\mathrm{K}_{I R}$ ( $0 \mathrm{I}_{\mathrm{IR}}$ ), are derived assuming that the kinetic effects are negligible. However, the Griffith energy balance for a fast running crack must include the kinetic stress component as well. The corresponding dynamic stress intensity factor, $K_{I} D Y N$, will depend upon the crack velocity. The relationship between $K_{I}{ }^{D Y N}$ and crack velocity, $\dot{a}$, is closely associated with such phenomena as crack branching or bifurcation and crack arrest. 
The fracture of an elastic medium is accompanied by the emission of stress waves from the tip of the propagating crack [20]. The stress waves can be either dilatational, which include compressive and tensile stress waves, or distortional, which are shear stress waves. The stress wave emission occurs as a result of the release of stresses associated with the crack tip region [21].

In general, $K_{T}{ }^{D Y N}$ is a function of the specimen geometry, loading, and crack velocity; i.e.,

$$
K_{\mathrm{I}} \mathrm{DYN}=\mathrm{f}(\mathrm{a}, \dot{a} \text {, geometry, loading })
$$

where a is the crack length. If the dynamic fracture toughness, KID, is considered to be a material property, the crack tip equation of motion is $\{27\}$

$$
K_{T}{ }_{T} \text { YN (2, } \dot{a} \text {, genmetry, loaring) }=K_{\underline{I D}}
$$

The analysis of dynamic crack propagation is made more complex by the fact that the crack tip stress state is affected by the stress waves reflected at the free boundaries. If the effect of such waves is ignored, one may write

$$
K_{I}{ }^{D Y N}=f(\dot{a}) K_{I} S T=K_{I D}
$$

where $K_{I} S T$ is the static stress intensity factor. Since $f(\dot{a}) \rightarrow 1$ as $a \rightarrow 0$, the crack arrests when the static stress intensity factor, $K_{I} S T$ equals $K_{I D}$. The ASME Code procedure [26] for crack arrests in nuclear pressure vessels is based on the assumption that arrest occurs when $\mathrm{K}_{T} \mathrm{ST}$ equals the so-called arrest toughness value, $\mathrm{K}_{\mathrm{I} a}$, which is considered to be a material property. However, the usefulness of the $\mathrm{K}_{\mathrm{Ia}}$ approach depends on whether it gives predictions that are sufficiently accurate for practical purposes.

\section{FRACTURE MECHANICS METHODS APPLICABLE TO ROCKS}

It is generally believed that most geological materials fracture in a brittle manner under unconfined conditions [31]. Therefore, most investigations involving fracture of rocks employ the concepts of LEFM $[22,23]$. However, the fracture of most types of rocks is associated with large scale micro-cracking at the crack tip, and a nonlinear treatment could be more appropriate for such cases. The nonlinear crack tip zone can be considered to be analogous to the yielding zone in a cracked elastic-plastic material under small-scale yielding (SSY) conditions. The SSY condition is defined as that having a small nonlinear zone compared to the overall dimensions of the cracked body. The nonlinear zone size at the onset of crack growth is proportional to $\left(\mathrm{K}_{\mathrm{IC}} / \sigma_{0}\right)^{2}$ where $\sigma_{0}$ is the limit stress [24]. Rock materials usually have low limit stresses in tension, and the corresponding nonlinear zone could be substantially large.

\subsection{Fracturing of oil shale}

Most types of rocks found on earth àre anisotropic. However, a large variety of sedimentary rocks have one axis of symmetry and are termed transversely isotropic materials, oil shale being a typical example. These 
materials could be quite homogeneous and isotropic in their planes of bedding [32]. However, the properties may change from layer to laver; and in a size scale which includes the separation between bedding planes, the material may be relatively anisotropic. $0 i l$ shale is found in bulk quantities in many parts of the world, including the United States, and, depending on the location, may contain $40 \%$ or more of organic material known as kerogen [36]. It has been suggested that in-situ processes are the most economical means for the extraction of organic matter from oil shale $[29,30]$. Also, it eliminates the need to dispose of the spent shale. Moreover, in the case of modified in-situ method, it is the most reasonable way for processing oil shale that must be left underground for support in conventional mining operations. In-situ retorting of oil shale requires the fragmentation or rubbiization of the material in order to create the permeability necessary for the subsequent burning. Blasting techniques are generally used to create in-situ retort rubble beds, and the development of this technology is largely inhibited due to the lack of understanding of rock fragmentation processes. Proper blast design needs a prior knowledge of the physical properties, including the fracture properties, of rock and an understanding of the fundamental fracture processes which take place during blasting. Edl [28] has emphasized the necessity for carrying out investigations leading to the determination of fracture processes that operate during explosive fragmentation of rocks. Such information would be useful for the rational design of conventional full scale blasts, assessing the feasibility of radical new blasting techiques, and for developing mathematical or numerical blasting models. The difficulties associated with studying the explosive fragmentation process involves [70]:

(a) Explosive fragmentation is a fast and dynamic event which lasts for only a fraction of a second. The design of measuring devices for responding to such fast processes may pose a problem.

(b) It may be difficult to design instrumentation that can withstand the extremely hostile environment prevailing in the vicinity of a blasthole during a blast and yet be expected to provide accurate and meaningful observations.

(c) The explosive fragmentation is complicated by the existence of such factors as stress waves, material defects, and high gas pressures, and its exact nature has not been fully understood.

The stress fields associated with rock fracturing is not always uniaxial but, rather, biaxial and triaxial. Compressive fracture of rock structures is very often associated with mixed mode failure. The Mohr-Coulomb fracture criterion [9] which assumes that the fracture occurs due to the attainment of a maximum shear stress has been partially successful in describing compressive failure in rock materials. However, most rocks do not fail at planes inclined at about $45^{\circ}$ to the direction of the principal stress direction as prescribed by the Mohr-coulomb criterion. The critical stress intensity factor theory [10] which suggests that the crack growth occurs when the stress intensity factor reaches a critical value leads to a criterion given as

$$
f_{1}\left(K_{I C}, K_{I I C}\right)-f_{2}\left(K_{I}, K_{I I}\right)=0
$$


where $K_{I}$ and $K_{I I}$ are the stress intensity factors of Mode $I$ and Mode II, respectively. The relationship in Equation (23) is known only for Mode $I$ and Mode II cases. However, for mixed mode cases involving both the modes, the precise relationship is not yet known. The minimum strain energy density criterion [7] has been successful in predicting the critical state of crack initiation, as well as the direction of growth under mixed mode loading. For example, in the biaxially loaded plate containing a central crack (Fig. 6), the crack growth does not occur along the plane of the crack, but in some other direction which is determined by the minimum strain energy density theory. From Equation (14), it follows that fracture occurs when the strain entrgy density reaches a critical value; i.e.,

$$
\frac{\Delta W}{\Delta V}=\left(\frac{\Delta W}{\Delta V}\right)_{c}=\frac{S_{c}}{r_{c}}
$$

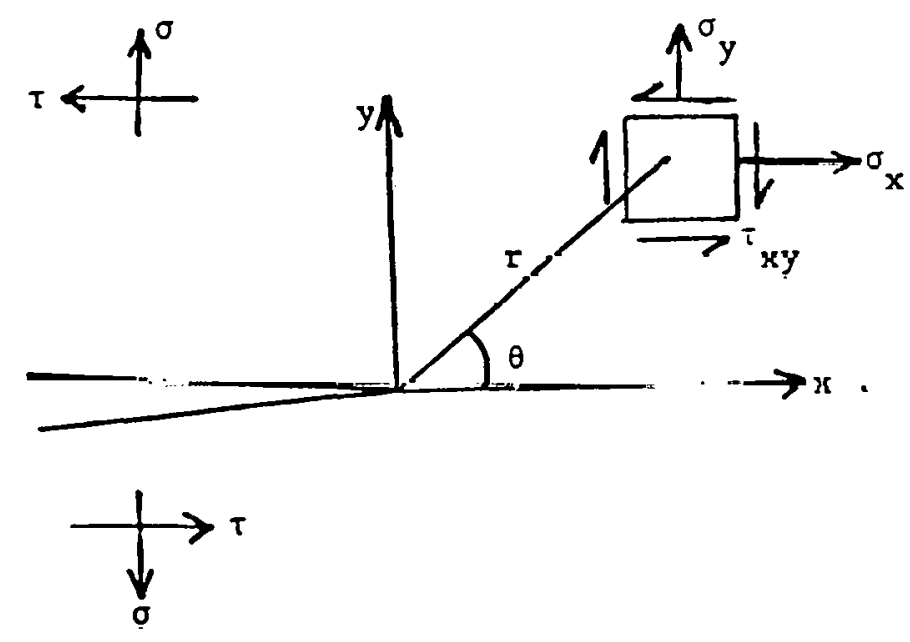

Figure 6. Sharp crack under biaxial loading ( $\sigma$ and $\tau$ are crack opening stress and in-plane shear stress, respectively.)

and the corresponding crack growth direction $\theta_{0}$ may be determined by considering the minimum value of strain energy density as [25]

$$
\frac{\partial}{\partial \theta}\left(\frac{d W}{d V}\right)=0, \frac{\partial^{2}}{\partial \theta^{2}}\left(\frac{d W}{d V}\right)>0
$$


The critical strain energy density, $(\Delta W / \Delta V)_{c}$, and the characteristic length, $r_{c}$, are considered to be material constants. For fracture of elastic materials, $\mathrm{dW} / \mathrm{dV}$ may be determined as [25]

$$
\frac{\mathrm{dW}}{\mathrm{dV}}=\frac{\mathrm{s}}{\mathrm{r}}
$$

and

$$
S=a_{11} K_{I}^{2}+2 a_{12} K_{I} K_{I I}+a_{22} K_{I I}^{2}
$$

where $S$ is the strain energy density factor and $a_{i j}$ are functions of material properties and angle $\theta$. The critical state of crack initiation and direction is determined by Equations (24) and (25). This theory may be extended for fracture involving lodes I, II, and III as well.

\subsection{Physical properties of oil shale}

A complete characterization of a transversely isotropic material requires the determination of five nonlinear "constants;" namely, $E_{1}, E_{3}, v_{12}, v_{31}$ and $G_{13}$ where axes 1 and 2 are along the isotropic planes, and axis 3 is the axis of symmetry. The Department of Civil Engineering of the University of Wyoming in cooperation with the U.S. Department of Energy, Laramie Energy Technology Center, has performed a series of investigations to devise methods for the complete mechanical characterization of transversely isotropic materials [29-31, 33-38] and has used this knowledge to determine the properties of Colorado, Utah, Wyoming, and other oil shaies. The properties of oil shale vary with the applied stress level; therefore, the use of mechanical tests is preferred to acoustical methods [30], which are more difficult to perform under different stress levels.

Chong, et al. [36] found that Young's modulus of oil shale is infuenced by organic volume and strain-rate. Organic rich shale vields lower Young's modulus in comparison with lean shale. For the same richness of the shale, the higher strain-rates of the material showed higher Young's modulus than that of lower strain-rates. The ultimate compressive fracture stress, too, has a similar variation showing a decreasing trend with organic volume and an increasing trend with strain-rate. The ultimate strain at fracture has been found to be independent of the strain-rate, but dependent upon the organic volume showing a linearly increasing relationship with richness. Chong, et al. [30] have also derived stiffness coefficients which depend on the applied stress levels and on the organic volume of oil shale using a piecewise linear model.

Several investigators have suggested methods to determine fracture toughness of rock material, assuming that the material were isotropic [42-45]. Some of the investigations have not considered the minimum dimensional requirements necessary for a valid plane strain fracture toughness value, even though Schmidt [44] suggests that ASTM size criterion, as given in expression 
(18), is appropriate for rock materials as well. Schmidt [45] and Ingraffea, et al. [46] have also reported that oil shale produces substantial stable crack growth before failure, both under tensile and compressive loadings. The fracture toughness is sensitive to the crack orientation with respect to the bedding planes, with the highest value for the divider geometry, lowest for short transverse, and intermediate for arrester [45]. Hence, the tendency for a crack to propagate in the direction of the bedding planes is higher than in any other direction. It has a strong dependency on organic volume, too, showing a decrease in magnitude with increasing richness.

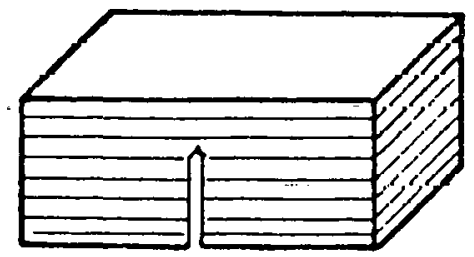

Arreter

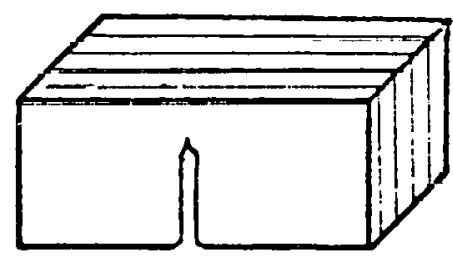

Divider

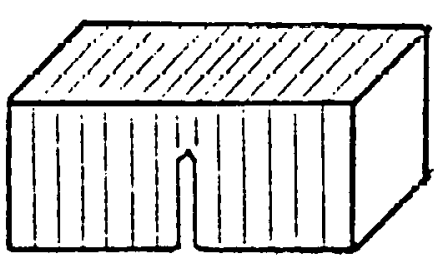

Short Transverse

Figure 7. Specimen configurations showing crack orientations with respect to the bedding planes

The ductility and toughness of oil shale increase with increasing confining pressure [31]. As a result, confining pressure affects most physical properties of sedimentary rocks, including fracture toughness and stress-strain relationship $[30,45]$. Even though most oil shale beds have relatively shallow overburden, the degree of dependency of fracture toughness on confining pressure, as well as high strain-rates, needs to be established. This information is required for the design of blasts which are associated with high strain-rates.

\subsubsection{Experimental determination of fracture toughness of lavered rocks}

oil shale is a layer material which is categorized as transversely isotropic. Hence, its fracture properties are highly dependent upon the crack orientation with respect to the bedding planes. Exact solutions related to crack border stress intensity tactors are avallable only tor izmited cases where the crack lies in a plane of elastic symmetry. Kassir and Sih [47] have presented the cases of penny-shaped cracks of circular and elliptic shapes whose planes are perpendicular to the axis of beddings. They have shown that stress intensity factors are the same as those for the corresponding isotropic cases if the normal tractions on the upper and lower faces of the cracks are self-balanced. However, displacements and stresses are different from those of the corresponding isotropic cases. Due to the difficulties associated with deriving exact solutions for general crack cases, characterization of fracture properties relies heavily on experimental and numerical methods. Attempts have 
been made to use the fracture mechanics test procedures, which were developed specifically for metallic materials, directly to rock. However, there are a few problems with such an approach. Firstly, the specimens that are used for standard fracture toughness test procedures, such as the ASTM E399 method, require a great deal of machining which is expensive and difficult to accomplish in rock. Secondly, ASTM E399 standard practice recommends that the fatigue preloading should not exceed 80 perecent of the estimated $K_{I C}$ value of the material, and this load level, in general, is not sufficient for the propagation of a fatigue precrack in a rock specimen. Thirdly, most of the experimental methods used for crack length measurement in metal specimens are not readily adaptable for rock. For example, the electrical potential drop method cannot be used with rock material as it is a bad conductor, and the high temperature oxidation procedure is also not applicable for rocks. Perhaps, only the unloading compliance method of crack length determination would be adaptable for specimens made of rock. Fourthly, the "cored" rock samples are of cylindrical geometry, and it may be difficult to satisfy the specimen size criteria necessary for a valid plane strain fracture toughness value, although the required minimum sizes are expected to be much smaller for rock materials than those for metals as given in ASTM E399 standard practice. It is believed that a deliberate introduction of a precrack would alter the natural fracture properties of an oil shale specimen. Paulding [48] has suggested a test method which makes use of a solid cylindrical specimen made of partially broken material. The specimens were initially loaded to just below their fracture strength so that some "natural" precracks would be introduced. The crack growth was studied in relation to the change of volumetric strain and the increase in porosity. By employing a jacketed specimen with a central core, it is possible to extend this method to determine the effect of gas pressure as well. Higher strain rates may also be used to simulate conditions under an explosive event. This method has disadvantages in that the point of crack initiation is difficult to be determined accurately and that the process of preloading for the introduction of cracks in the specimen could lower its resistance to fracture.

Johnson, et al. [69], have proposed a "burst test" method for rock materials using an internally pressurized, thick-walled cylindrical specimen having one or two radial prenotches. Specimens are "jacketed" by placing a soft impermeable liner inside the bore of the cylinder to prevent the fluid from entering the cracks, so that the fluid pressure would act only on the inner wall of the cylinder leaving the crack surfaces free from loading. The important feature for this geometry and loading is that the stress intensity factors for both one and two radial crack cases show a broad relative minimum over a wide range of crack lengths, provided the ratio of outside and inside diameter is large. As a result, cracks tend to grow in a stable manner before reaching the point of fast fracture, thus making the initial crack length a less critical parameter for the determination of fracture toughness. Hence, $K_{\text {IC }}$ may be determined with a knowledge of the internal pressure at fracture and with an approximate value of the initial crack length. This is an advantage of the method as the latter parameter is difficult to measure accurately in rock specimens. The disadvantages of this method for applications to rock fracture are the presence of one or more prenotches and that the characteristic increase 
in resistance for stable crack growth might interfere with the expected pattern of variation of the stress intensity factor with crack length.

Rock test samples are usually "cored" from larger cylindrical cores; therefore, it is generally convenient and economical to use cylindrical specimens as standard facture toughness specimens. The split cylinder test shown in Fig. 8 is a promising method to determine fracture toughness. It has been used extensively in literature [34, 38, 49-52] for the determination of physical properties of rock materials. The probiem of anisotropy in laminated oil shale is overcome by using short samples perpendicular to the bedding planes. The classical theory shows that a tensile stress component equal to $\frac{2 P}{\pi d}$ acts normal to the plane of load application and in the central part of the cylinder [38]. Experiments have snown that this stress component causes failure of specimens made of rock and other brittle materials. The stress

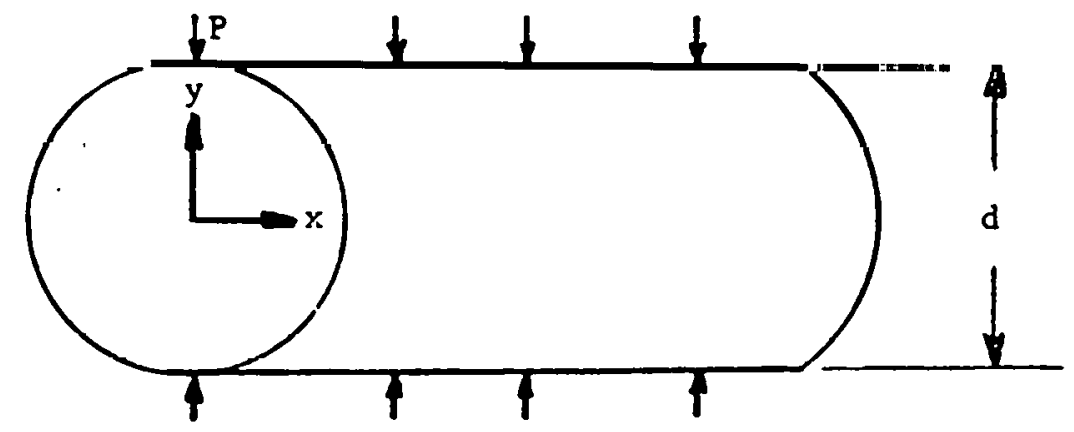

Figure 8. Split cylinder test configuration. The specimen has bedding planes perpendicular to its axis of symmetry.

distribution is non-uniform in areas close to the point of load application. However, there is a remarkably uniform tensile stress distribution in the inner part of the cylinder $\{29\rfloor$. Due to the occurrence ot tensile stress in $x$ direction along the loaded diameter, the pre-existing cracks in the plane of load application may play a significant role in crack initiation and growth process. The fracture stress of large specimens would be particularly affected due to the presence of a large number of such stress risers. The fracture toughness of the material may be determined by measuring the peak force required to completely fracture the specimen. An appropriate initial flaw size may be assumed. This test specimen has a preferred orientation of fracture plane due to the predominance of horizontal tensile stresses along the vertical diameter and represents the natural fracturing process better than most other specimens due to the absence of an artiticial pre-notch.

A double cantilever beam (DCB) specimen with a pre-notch has been used for fracture tests of brittle, as well as ductile material [53-55]. A cylindrical DCB specimen with a "V" slot, known as a short rod specimen, has been used by Barker [56] to determine fracture toughness of rock materials. Such configurations can be employed to determine fracture toughness conveniently, as the only measured parameter is the maximum load required to completely fracture the sample. Specimen compliance is determined by analytical means or by 
experiments; and, in general, no load-displacement plot is required. The "reinforced" DCB specimen shown in Fig. 9 has its major axis normal to the
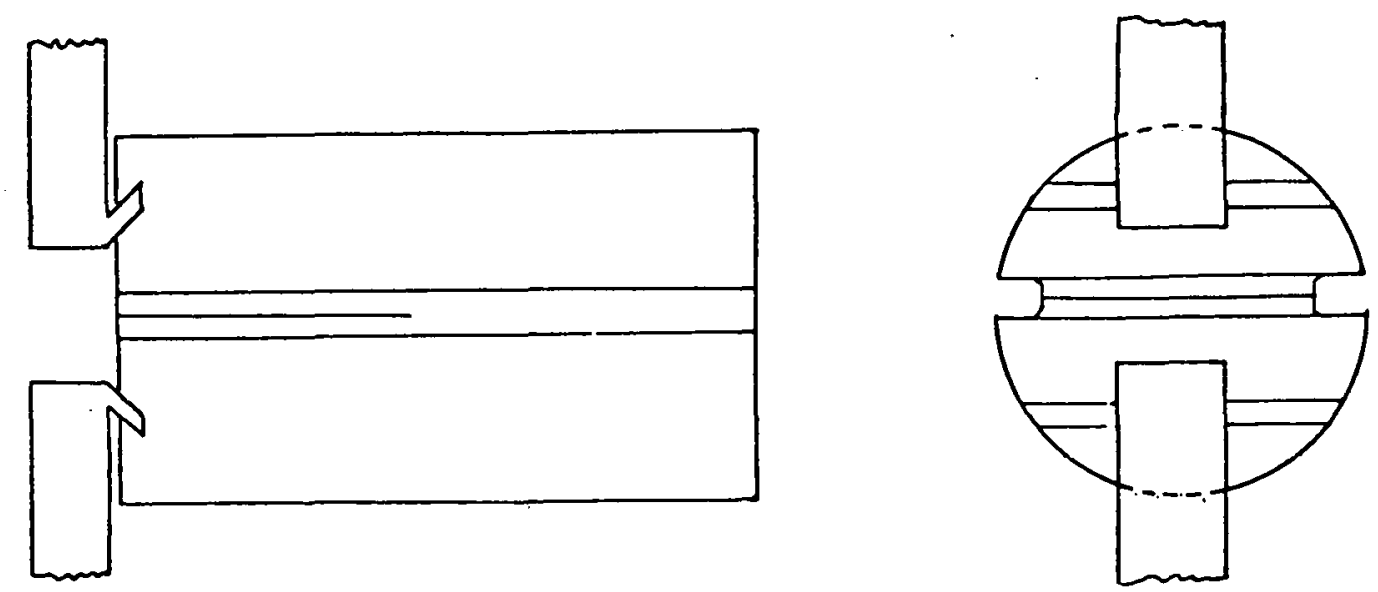

Figure 9. Reinforced double cantilever beam with possible loading fixtures shown.

bedding planes. The groove of the specimen containing the crack runs along the center line of the specimen and helps to maintain a stable crack growth. The height of the groove is chosen to be small in comparison with the diameter so that it would help in achieving plane strain conditions at the crack tip, even if the ratio of groove width/diameter is small. The crack tip is maintained straight and perpendicular to the axis of specimen. A "natural" crack may be introduced using fatigue preloading, and the pre-crack length may be determined by making use of a dye. The length/diameter ratio is chosen to be reasonably small. A pair of simple loading grips that engages into shallow slots machined on the free vertical face of the specimen, or some other loading fixtures, may be used. The specimen is pulled apart until fracture, and the critical fracture toughness may be determined using the peak load. The innerent geometric stability of the reinforced DCB specimen makes it suitable to be used with all brittle materials. The geometry is simple and is convenient to be machined from rock materials. Due to its remarkable stability for the initial crack growth, the DCB specimen has been used for dynamic fracture toughness testing as well [53]. This specimen is more suitable for the evaluation of fracture toughness at high strain-rates than most other fracture specimens.

\subsection{Simulation of crack initiation and growth using numerical methods}

More modern approaches to the quantification of stable as well as dynamic fracture events generally use a computational approach. The finite element method [57] has been proven to be versatile in applications to structural, solid mechanics, fluid mechanics, and heat transfer problems. Early development of the finite element method was based on triangular constant 
stress elements. However, elements having an increased number of nodes have been used in recent years, resulting in a corresponding increase in accuracy. In particular, the quadratic isoparametric elernents which exhibit a one-to-one correspondence between Cartesian and Curvilinear coordinates have been found to yield very accurate results.

Consider an eight-noded isoparametric crack tip element having three of its nodes falling at the crack tip, as shown in Fig. 10. If the three nodes falling at the crack tip are bound, and the midside nodes adjacent to the crack tip are shifted to the quarter points near the crack tip, the strain function
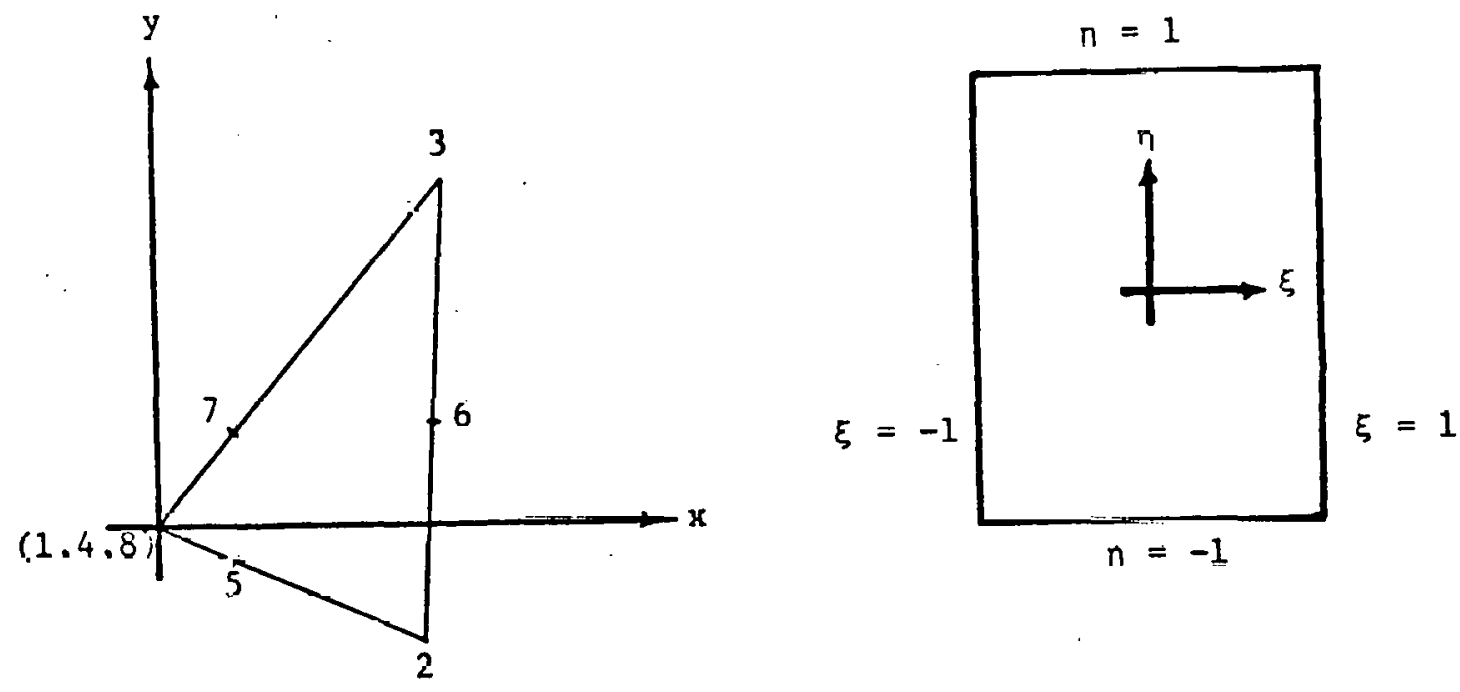

Figure 10. Quarter point isoparametric crack tip element

will assume the form of the typical crack tip elastic singularity given as $1 / \sqrt{x}$ [58]. These elements satisfy convergence criteria, and the incorporation of these to a standard finite element program does not require additional programming effort. They have been shown to yield accurate results with mixed mode fracture problems involving Mode I and Mode II loadings as well [59]. The near tip stress and displacement field is determined with the crack tip singularity represented by quarter point elements, and the stress intensity factor may be determined by means of a relationship such as expression (1). The finite element method may be used for the solution of problems involving dynamic fracture as well. 


\section{CONCLUSIONS AND RECOMMENDATIONS}

This study broadly dealt with the principles of fracture mechanics which would be useful for the characterization of fracture properties of rock materials under brittle and ductile fracture conditions. Relevant theoretical principles, a numerical approach, and experimental methods for the determination of fracture properties were discussed. The conciusicns arising out of this study and recommendations are summarized as follows:

A) The classical theory of fracture mechanics postulates that all materials contain flaws or cracks which act as stress risers, and that fracture initiates when the stress intensity factor associated with the crack tip strain field reaches a critical value, which is often referred to as fracture toughness. It is considered to be a material property under plane strain conditions. This theory can be conveniently applied for fractures of cracked bodies having simple geometries and under simple loading situations. However, the analysis becomes tedious for cases of fractures involving complex geometries and complicated loading systems such as mixed mode loading. J-integral method and strain energy density theory (S-theory) are suitable alternatives for such applications. Jintegral theory is satisfactory for the analysis of linear as well as nonlinear fracture as, for example, that of rock materials under highly applied stresses. However, its applications are limited by the fact that the J-integral is based on the deformation theory of plasticity which is violated in the presence of stress reversals and highly non-proportional loadings such as those experienced during fast fracture. S-theory has been proven to be satisfactory for brittle fracture, including crack growth. It has the added capability of being able to predict the direction of initial crack growth, as well as the extent of growth.

B) Explosive fragmentations involve high strain-rates $\left(10^{1}-10^{3}\right.$ $\mathrm{Sec}^{-1}$ ), and they produce fractures which propagate at high velocities. Hence, it is necesary to consider dynamic ettects in characterizing fracture properties during explosive events. It is required to investigate the effect of stress waves, strain-rate, and crack velocity on the dynamic fracture tougnness of rock materials. Crack bifurcation and arrest are also associated with dynamic fracture events.

C) Theoretical solutions for simple cases of fracture of transversely isotropic materials are available in literature. However, most practical cases involve complex geometries and loading situations which call for numerical solutions. Finite element method has been proven to be satisfactory in the solution of problems involving both quasi-static and dynamic fracture. Quarter point crack tip elements are convenient to be used with most general purpose finite element computer programs and yield accurate results for fracture of brittle materials. They have limited applications in cases of nonlinear fracture, as well.

D) Fracture toughness of oil shale depends on the presence of stress risers such as microcracks and their orientation with respect to bedding planes. 
Hence, a complete fracture characterization should include average fracture properties in arrester, divider, and short transverse directions.

E) It has been established that ductility of oil shale increases with increasing confining pressure. Fracture toughness and ductility are closely related properties, and there would be a corresponding variation of fracture toughness with confining pressure.

F) The organic volume of oil shale affects its fracture properties to a large extent. It is known that fracture toughness has a decreasing trend with increasing richness of oil shale. It is required to devise fast, convenient, and accurate methods for such characterization.

G) Cylindrical specimens, internally pressurized thick-walled vessels, split cvlinder test specimens, and reinforced double cantilever beam (DCB) specimens are suggested as suitable candidates for "standard" fracture specimens. All four types of specimens may be prepared from cylindrical rock cores with very little machining. Cylindrical specimens and split cylinder specimens have an advantage in that they are both free from artificial pre-notches: Moreover, their loading arrangements are simple--a property that makes testing convenient and fast. The internally pressurized cylindrical specimen test method has the advantage that fracture toughness may be determined with a knowledge of the burst pressure and an approximate measurement of the crack length. On the other hand, the DCB specimen has a characteristic geometric stability which makes it very appropriate for tests under quasi-static, as well as dynamic fracture conditions. Also, it is necessary to investigate and establish a suitable test procedure and its limitations and constraints. An effort is being made by ASTM and its Subcommittee E 24.07, too, toward this end.

\section{ACKNOWLEDGMENTS}

Speedy and accurate typing of this report by Mrs, Anita Biggs is gratefully acknowledged. 


\section{REFERENCES}

1. Griffith, A. A., "The phenomena of rupture and flow in solids," Philosophical Trans Roval Soc., A221, 1921, Pp. 163-171.

2. Orowan, E., Trans. Inst. Engrs. Shipbuilders, Scotland, Vol. 89, $1945, \mathrm{pp} .165$.

3. Irwin, G. R., "Relations of stresses near a crack to the crack extension force," 9th Int. Congr. Appl. Mech., Vol. VIII, paper 101, Univ. of Brussels, 1956 .

4. Barenblatt, G. I., "The formation of equilibrium cracks during brittle fracture; General ideas and hypotheses; Axialy summetric cracks,"! J. Appl. Hech. Vol. 23, 1959, pp. 622-636.

5. Broberg, K. B., "Critical review of some theories in fracture mechanics," Int. J. Fract. Mech., Vol. 4, 1968, Pp. 11-18.

6. Rice, J. R., "A path-independent integral and the approximate analysis of strain concentration by notches and cracks," Trans. ASME, J. Appl. Mech., Vol. 35, 1968, Pp. 379-386.

7. Sih, G. C., "Analytical modeling, crack growth characteristics," Fracture Mechanics, (eds. Perrone, et al.), The Univ. Press of Virginia, $\overline{1978 .}$

8. Wells, A. A.,"Unstable crack propagation in metals: Cleavage and fast fracture," Crack Propagation Sumposium, Cranfield, England, 1961.

9. Jaeger, J..C. and Cook, N. G. W., Fundamentals of Rock Mechanics, John Wiley \& Sons, Inc., NY, 1976, P. 324.

10. Fracture Toughness Testing and Its Applications, ASTM STP 381, Philadelphia, PA, 1965.

11. Liu, H. W., "On the fundamental basis of fracture mechanics," Engrg. Frart. Merh, Vol. 1.7, 1983, Pp. 425-438.

12. Begley, J. A. and Landes, J. D., "The J-integral as a fracture criterion," Fracture Toughness, ASTM STP 514, 1972, PP. 1-20.

13. Sih, G. C., (ed.), Chapter 4, Methods of Analvsis and Solutions of Crack Problems, Noordhoff, 1973 .

14. Burdekin, F. M. and Stone, D. E., "The crack opening displacement approach to fracture mechanics in yielding materials," J. Strain Analysis,

Vol. 1, 1966, pp. 145-153.

15. Gurney, C. and Hunt, J., "Quasi-static crack propagation," Proc. Roy. Soc., London, A299, 1967, pp. 508-524. 
16. "Standard method of test for plane strain fracture toughness in metallic materials," ASTM E399-S1, American Societv for Testing and Mlaterials, NY, 1981.

17. Irwin, G. R., "Fracture mechanics," Structural Niechanics (Proceedings of First Naval Symposium), Pergamon Press, 1960 .

18. Duvall, W. J. and Atchison, T. C., "Rock breakage by explosives," U.S. Bureau of Mines, RI 5356, 1957.

19. Hino, K., "Fragmentation of rock through blasting and shock wave theory of blasting," Colorado School of Mines Quarterlv, Vol. 51, No. 3, 1956, pp. 191-209.

20. Miklowitz, J., "Elastic wave created during tensile fracture - The. phenomenon of a second fracture," J. Appl. inech., Vol 3, 1953, pp. 122 .

21. Kolsky, H., "Wave propagation effects and fracture," Brown Univ., Report No. 11,1974 .

22. Hoagland, R. G., et al., "Influence of microstructure on fracture propagation in rocks," Rock Mech., Vol. 5, 1973, pp. 77-106.

23. Schmidt, R. A., "Fracture toughness testing of rock," Closed Loop, Vol. 3, Nov., 1975.

31. Gavigan, W. J., Kc, J. S., and Liu, H. W., "Lucal and gross deformartóns in cracked metallic plates," Int. J. Fract. Mech., Vol. 9, 1973, pp. 255-266.

25. Sih, G. C., ed, "A special theory of crack propagation," Methods of Analvsis and Solutions of Crack Problems, Noordhoff International Publishing, 1973 .

26. ASME Boiler and Pressure Vessel Code, Aunerican Society of Mechanical Engineers, Section XI, Article A-\$300, 1975 .

27. Smith, E., "The crack tip stress intensification associated with crack propagation and arrest," Proceedings, 5th Int. Conf. Fracture,

1981, Cannes, France, Pp. 2215-2223.

28. Edl, John N., Jr., "Some aspects of explosive fragnentation and fracture mechanics of rock," unpublished report, Laramie Energy Technology Center, $1980,21 \mathrm{pP}$.

29. Chong, Ken P., Smith, John W., and Borgman, Eric S., "Ultimate tensile strengths of Colorado and Utah Oil Shales," 15th Intersocietv Energy Conversion Eng. Conf., Seattle, WA, August, $\overline{1980}, \overline{\text { pp. 285-290. }}$ 
30. Chong, K. P., Uenishi,.K., Smith, J. W., and Munari, A. C., "Non-Iinear three-dimensional mechanical characterization of Colorado Oil Shale," Int. J. Rock Mech. Min. Sci. \& Geomech. Abstr., Vol. 17, 1980, pp. $3 \overline{39}-\overline{347}$.

31. Chong, K. P., Chen, J. L., Dana, G. F., Sailor, S., "Triaxial testing of oil shale from the Devonian Chattanooga shale formation in Dekalb County, Tennessee," Dept. of Energy, Report No. DOE/LC/RI-83-5, March, 1983.

32. Dana, G. F. and Smith, J. W., "Oil yields stratigraphy of the Green River formation's Tipton Member at Bureau of Mines sites near Green River, WY," Bureau of Mines Report of Investigtions, 1972.

33. Chong; K. P., Smith, J. W., Chang, B., Hoyt, P. M., and Carpenter, H. C., "Characterization of oil shale under uniaxial compression," Proc.

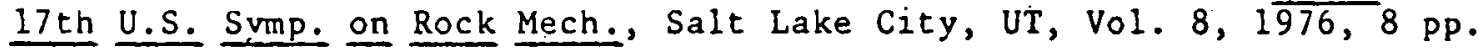

34. Chong, K. P., Smith, J. W., Roine, S, and Chang, B., "Mechanical properties of oil shale by "modififed" split cylinder testing," Proc. 1.8th U.S. Symp. on Rock Mech., Golden, Co, 1977, 5 pp.

35. Chong, K. P., Smith, J. W., and Khaliki, B., "Creep and relaxation of oil shale," Proc. 19th U.S. Svmp. on Rock Mech., Lake Tahoe, Nevada, $1978, \overline{8 \mathrm{pp}}$.

36. Chong, K. P., Hoyt, P. M., Smith, J. W., and Paulson, B. Y., "Effects of strain rate on oil shale fracturing," Int. J. Rock Mech. Min. Sci. $\$$ Geomemch. Abstr., Vol. 17, 1980, pp. 35-43.

37. Chang, B., Costello, K., Chong, K. P., and Smith, J, W., "Fatigue tests of oil shale," Proc. 19th U.S. Sump. on Rock Mech., Lake Tahoe, Nevada, 1978,6 pp.

38, Chong, K, P., Smith, J. W., Chang, B., and Roine, S., "Oil shale. properties by split cylinder method," J. Geotech. Engrg. Div. Am. Soc. Civ. Engrs., Vol 105, 1979, pp. 595-611.

39. Morris, C. E., "Elastic constants of oil shale," Explosively produced Fracture of Oil Shale, (compiled by W. J. Carter), LA-7164-PR, Los Alamos Scientific Lab., Los Alamos, New Mexico, 1978.

40. Olinger, B., Explosively Produced Fracture of Oil Shale, Annual Report, March 1976 - Harch 1977 (compiled by W. J. Carter), LA-6817-PR, Los Alamos Scientific Lab., Los Alamos, New Mexico, 1977, pp. 21-28.

41. Podio, A. L., Gregory, A. R., and Gray, K. E., "Dynamic properties of dry and water-saturated Green River shale under stress," Soc. Petrol. Engrs. J., 1968, pp. 389-404. 
42. Schmidt, R. A. and Huddle, C. W., "Effect of confining pressure on fracture toughness of Indiana limestone," Int. J. Rock Mech. Min. Sci.

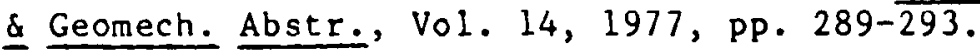

43. Abou-Sayed, A. S., "Fracture toughness, $K_{I C}$, of triaxially-loaded Indiana limestone," Proc. 18th U.S. Symp. Rock Mech., Keystone, $\mathrm{CO}, 1977$, p. 2A3-1.

44. Schmidt, R. A., "Fracture-toughness of limestone," Exp. Mech., May, 1976, pp. 161-167.

45. Schmidt, R. A., "Fracture mechanics of oil shale--Unconfined fracture toughness, stress corrosion cracking, and tension test results," Symp. Rock Mech. Keystone, CO, June, 1977, p. 2A2-1.

46. Ingraffea, A. R., Heuze, F. E., Ko, H. Y., dill Kunt, O., "Flacture propagation in rock: Laboratory tests and finite-element analysis," Proc. 17th U.S. Symp. Rock Mech., Snowbird, Ueah, Ảigusr, 1976, p. $5 \mathrm{C}_{4}-1$.

47. "Cracks in anisotropic materials," Three Dimensional Crack Problems, Kassir and Sih, eds., Noordhoff Int. Publishing, Leyden, 1975.

48. Paulding, B. W., Jr., "Techniques used in studying the fracture mechanics of rock," ASTM STP 402, 1966, PP. 73-85.

49. Fairhurst, C., "On the validity of the Brazilian rest for brittle materials," Int. J. Rock Mech. Min. Sci., Vol. 1, 1964, Pp. 535-546.

50. Hondros, G., "The evaluation of Poisson's ratio and the modulus of materials of a low tensile resistance by the Brazilian test," Australian J. of App. Sci., Vo1. 10, 1999, pp. 243-268.

51. Chong, K. P., "A new method for the mechanical testing of brittle materials," presented at the 8th U.S. National Congress of ApP. Mech., Univ. Calif., Los Angeles, 1978.

52. Colback, P. S. B., "An analysis brittle fracture initiation and propagation in the Brazilian test," Proc. 1st Int. Congress of the Soc. of

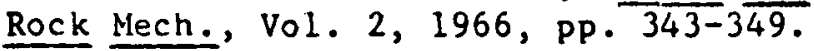

53. Kanninen, M. F., "An augmented double cantilever beam model for studying crack propagation and arrest," Int. J. traccure, vol. 9, 1973, pp. 83-92.

54. Gurney, C., Mai, Y. W., and Owen, R. C., "Quasi-static cracking of materials with high fracture toughness and low yield stress," Proc. Roval Soc. of London, A340, 1974, PP. 213-231. 
55. Sykes, J. L, and Chow, C. L., "On the measurement of fracture toughness of ductile materials with RDCB specimens," Proc. 2nd Int. Conf. of Mechanical Behavior of Metals, Boston (Am. Soc. of Metals), 1970, Pp. $1542-1546$.

56. Barker, L. M., "A simplified method for measuring plane strain fracture toughness," Eng. Fract. Mech, Vol. 9, 1977, pp. 36i-369.

57. Zienkiewicz, O. C., The Finite Element Method, McGraw-Hill Co., 1977.

58. Barsoum, R. S., "On the use of isoparametric finite elements in linear fracture mechanics," Int. J. for Num. Meths. in Engrg., Vol. 10, 1976, pp. 25-37.

59. Woo, C. W. and Kuruppu, M. D., "Use of finite element method for determining stress intensity factors with a conic-section simulation model of crack surface," Int. J. Fracture, Vol. 20, 1982, pp. 163-178.

60. Ingraffea, A. R. and Schmidt, R. A., "Experimental verification of a fracture mechanics model for tensile strength prediction of Indiana Iimestone," 19th U.S. Rock Mechanics Svmp., May, 1976, p. 247-253.

61. Hutchinson, J. W., "Plastic stress and strain fields at a crack tip," J. Mech. Phvs. Solids, Vol. 16, 1968, Pp. 337-347.

62. Rice, J. R. and Rosengren, G. F., "Plane strain deformation near a crack tip in a power law hardening material," J. Mech. Phys. Solids,

Vol. 16, 1968, pp. 1-12.

63. Fracture Toughnes Evaluation by R-Curve Methods, ASTM STP 527, 1973.

64. Hutchinson, J. W., and Paris, P. C., "The theory of stability analysis of J-controlled crack growth," in: Elastic-Plastic Fracture, ASTM STP 668, 1979, PP. 37.

65. "Standard practice for R-curve determination," Annual Book of ASTM Standards, ASTM ES61-81, part 10, 1981.

66. Liu, H. W. and Yang, C. Y., "Strip yielding model and fracture toughness of thin and tough plates," Proc. Int. Conf. Fract. Mech. Engrg. Appl., Banglore, India, 1979, PP. 26-30.

67. Schmidt, R. A. and Lutz, T. J., "K $K_{I C}$ and $J_{I C}$ of westerly graniteeffects of thickress and in-plane dimensions," in: Fracture Mechanics Applied to Brittle Materials, ASTM STP 678, 1979, pp. 166-182.

68 Krech, W. W., "The energy balance theory and rock fracture energy measurements for uniaxial tension," Proc. 3rd Int. Congr. ISRM, Nat. Acad. Sciences, Washington, D.C., 1974, Vol. 2A, PP. 167-173. 
69. Johnson, J. N., et al., "Analysis of fracture of hollow cylindrical and spherical rock specimens subjected to internal pressure with applications to underground nuclear containment," Terra Tek Rep. IR 73-50, Sept., 1973.

70. Edl, John N., Jr., "Some thoughts on a possible in-house rock fragmentation research effort," unpublished report, Laramie Energy Technology Center, 1982, 13 Pp.

71. Ouchterlong, F. "Review of fracture toughness testing of rock," Report DS 1980:15, Swedish Detonic Research Foundation, 1980. 